\title{
Diagnosis and staging of ocular surface squamous neoplasia
}

\begin{tabular}{|c|c|}
\hline \multicolumn{2}{|c|}{$\begin{array}{l}\text { Authors: } \\
\text { Roland Höllhumer } 1,2, \\
\text { Pamela Michelow } \\
\text { Susan Williams }{ }^{1} \text { (1) }\end{array}$} \\
\hline \multicolumn{2}{|c|}{$\begin{array}{l}\text { Affiliations: } \\
\text { }{ }^{2} \text { Department of } \\
\text { Ophthalmology, Faculty } \\
\text { of Neurosciences, University } \\
\text { of the Witwatersrand, } \\
\text { Johannesburg, South Africa }\end{array}$} \\
\hline \multicolumn{2}{|c|}{$\begin{array}{l}{ }^{2} \text { The Cornea Foundation, } \\
\text { Johannesburg, South Africa }\end{array}$} \\
\hline \multicolumn{2}{|c|}{$\begin{array}{l}{ }^{3} \text { Cytology Unit, National } \\
\text { Health Laboratory Service and } \\
\text { Department of Anatomical } \\
\text { Pathology, Faculty of Health } \\
\text { Sciences, University of } \\
\text { the Witwatersrand, } \\
\text { Johannesburg, South Africa }\end{array}$} \\
\hline \multicolumn{2}{|c|}{$\begin{array}{l}\text { Corresponding author: } \\
\text { Roland Höllhumer, } \\
\text { roland.hollhumer@wits.ac.za }\end{array}$} \\
\hline $\begin{array}{l}\text { Dates: } \\
\text { Received: } 25 \mathrm{~J} \\
\text { Accepted: } 21 \mathrm{C} \\
\text { Published: } 14\end{array}$ & $\begin{array}{l}\text { une } 2020 \\
\text { Det. } 2020 \\
\text { Dec. } 2020\end{array}$ \\
\hline \multicolumn{2}{|c|}{$\begin{array}{l}\text { How to cite this article: } \\
\text { Höllhumer R, Michelow P, } \\
\text { Williams S. Diagnosis and } \\
\text { staging of ocular surface } \\
\text { squamous neoplasia. } \\
\text { Afr Vision Eye Health. } \\
\text { 2020;79(1), a590. https://doi. } \\
\text { org/10.4102/aveh.v79i1.590 }\end{array}$} \\
\hline \multicolumn{2}{|c|}{$\begin{array}{l}\text { Copyright: } \\
\text { (c) 2020. The Author(s). } \\
\text { Licensee: AOSIS. This work } \\
\text { is licensed under the } \\
\text { Creative Commons } \\
\text { Attribution License. }\end{array}$} \\
\hline \multicolumn{2}{|l|}{ Read online: } \\
\hline 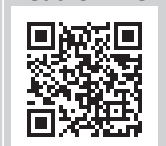 & $\begin{array}{l}\text { Scan this QR } \\
\text { code with your } \\
\text { smart phone or } \\
\text { mobile device } \\
\text { to read online. }\end{array}$ \\
\hline
\end{tabular}

Background: Ocular surface squamous neoplasia (OSSN) is the most common ocular tumour. The diagnosis of OSSN is based on clinical suspicion and confirmed by various diagnostic modalities, of which histology is the gold standard. With the move to less invasive management options such as topical chemo- or immunotherapy, less invasive diagnostic options have come to the fore.

Aim: The purpose of this article was to review the current staging and diagnostic modalities for OSSN with a focus on less invasive modalities.

Method: A literature review was performed for publications on ocular surface neoplasia and diagnostic modalities.

Results: Histology is the gold standard for diagnosing OSSN. Cytology has been shown to be a simple, repeatable and minimally invasive diagnostic modality, which also allows for additional testing such as polymerase chain reaction. Anterior segment optical coherence tomography provides a non-contact method of evaluating the ocular surface, with OSSN showing a thickened hyper-reflective epithelium, abrupt transition zone and demarcation line. Vital dyes are used less commonly with high sensitivity, but lower specificity for OSSN. Finally, confocal microscopy provides en-face images of the ocular surface, with OSSN showing a classic 'starry night' appearance.

Conclusion: Histology remains the gold standard for diagnosis; however, with the increasing use of topical therapy for OSSN, there has been an increase in the uptake of less invasive diagnostic modalities.

Keywords: conjunctival neoplasm; squamous cell cancer; conjunctival imprint cytology; liquid-based cytology; conjunctival histology; optical coherence tomography; confocal microscopy; methylene blue; toluidine blue; ultrasound biomicroscopy.

\section{Introduction}

Ocular surface squamous neoplasia (OSSN) is the most common ocular tumour and encompasses conjunctival intra-epithelial neoplasia (CIN), squamous cell carcinoma in-situ (CIS) and invasive squamous cell carcinoma. ${ }^{1}$ Its incidence varies according to geographical location, with the highest incidence being reported within $30^{\circ}$ of the equator and in countries with a high prevalence of the human immune-deficiency virus (HIV). ${ }^{2,3}$

The most common associations are ultra-violet B exposure, human papilloma virus (HPV) and HIV infection. . $3,3,5^{-1}$ Ultra-violet B exposure induces mutations of the P53 tumour suppressor gene as does the E6 oncoprotein in HPV-related neoplasia. The E7 HPV oncogene alters the cell cycle, whilst HIV impairs the bodies' tumour immune-surveillance mechanisms. ${ }^{6}$

A diagnosis of OSSN is initially suspected based on the clinical features of a conjunctival mass. ${ }^{7}$ Tests are then performed to confirm the diagnosis. Histological diagnosis is the gold standard; however, there has been a move to less invasive tests with the increased use of topical chemo- or immunotherapy in the treatment algorithms. ${ }^{3,8,9}$ The purpose of this article was to review the current staging and diagnostic modalities.

\section{Staging}

Ocular surface squamous neoplasia can be staged according to histopathology and the American Joint Committee on Cancer (AJCC) staging. ${ }^{3,10}$ Dysplastic cells proliferate from the basal conjunctival epithelium to involve the full epithelium before breaking through the 
basement membrane. ${ }^{1}$ On histopathology, dysplastic cells within the epithelium are called CIN., ${ }^{1,3}$ If the basal third is involved, it is a CIN I lesion (mild dysplasia), basal two-thirds a CIN II (moderate dysplasia) and almost full thickness a CIN III (severe dysplasia). ${ }^{1}$ If the full-thickness epithelium consists of dysplastic cells, it is called squamous CIS. ${ }^{1}$ Once the basement membrane has been breached, it becomes invasive squamous cell carcinoma. ${ }^{1}$

The AJCC staging protocol was updated in 2016 (Table 1), and this emphasised the importance of a staging system because of the increased incidence of OSSN associated with the HIV pandemic. ${ }^{10}$ This system uses the well-established TNM staging, describing the tumour characteristics (T), lymph node involvement $(\mathrm{N})$ and metastasis $(\mathrm{M}) \cdot{ }^{10}$ Tumour characteristics are based on direct and slit lamp examination, gonioscopy and dilated fundoscopy to assess the extent of the lesion.,10,11 Ocular surface squamous neoplasia spreads primarily by direct extension, and therefore imaging studies may be required to assess the extent of spread..$^{10}$ Imaging modalities that can be employed include anterior segmentoptical coherence tomography (AS-OCT), ultra-sound biomicroscopy (UBM), B-san ultrasonography, computed tomography or magnetic resonance imaging., ${ }^{3,10}$ Depth of the lesion can also be determined by histology. ${ }^{10}$ Lymph nodes are primarily assessed by clinical palpation, with the preauricular, mandibular and cervical lymph nodes rarely involved. ${ }^{10}$ These tumours rarely metastasise; however, spread of these tumours to the lungs and bone has been previously described. ${ }^{12}$

A limitation of the AJCC staging system is that most OSSN is histologically graded as CIN I to CIN III, but the staging combines these tumours into a single stage (Tis). ${ }^{10,11}$ The staging has also been misinterpreted in studies with corneal extension classified as a T3 tumour..$^{13}$ Corneal extension of tumours is not an invasion of an adjacent structure, as the basement membrane mostly remains intact. ${ }^{10}$ The AJCC classification therefore relies on histological grading for classification. A staging system is a useful modality to grade the disease and relate this to prognosis, but it has been shown that this staging system does not

TABLE 1: American Joint Committee on Cancer staging for ocular surface squamous neoplasia.

\begin{tabular}{ll}
\hline T category & T criteria \\
\hline TX & Primary tumour cannot be assessed \\
T0 & No evidence of primary tumour \\
Tis & Carcinoma in situ \\
T1 & $\begin{array}{l}\text { Tumour ( } \leq 5 \mathrm{~mm} \text { in greatest dimension) invades through the conjunctival } \\
\text { basement membrane without invasion of adjacent structures }\end{array}$ \\
T2 & $\begin{array}{l}\text { Tumour ( }>5 \mathrm{~mm} \text { in greatest dimension) invades through the conjunctival } \\
\text { basement membrane without invasion of adjacent structures }\end{array}$ \\
T3 & Tumour invades adjacent structures (excluding the orbit) \\
T4 & Tumour invades the orbit with or without further extension \\
T4a & Tumour invades orbital soft tissues without bone invasion \\
T4b & Tumour invades bone \\
T4c & Tumour invades adjacent paranasal sinuses \\
T4d & Tumour invades brain \\
\hline
\end{tabular}

Source: Amin MB, Edge SB, Greene FL, et al., editors. AJCC cancer staging manual. Cham: Springer International Publishing; 2017 [cited 2019 Dec 17]. Available from https://www.springer.com/gp/book/9783319406176 correlate with prognostic outcomes because of the described shortcomings. ${ }^{11,14}$

\section{Clinical}

Symptoms of OSSN are typically vague and non-specific. They include redness, foreign body sensation and in diffuse or advanced cases a reduced visual acuity.1,15 Presentation is mostly unilateral, with bilateral cases occurring in immune-suppressed patients. ${ }^{15}$ Clinical features are variable but may include an elevated lesion with vascularisation, pearly grey appearance and a variable amount of pigmentation. ${ }^{1}$ The presence of leucoplakia (Figure 1a), feeder vessels (Figure 1a, f, h), gelatinous appearance and larger size have been shown to be predictive of OSSN, whilst a mass that is immobile is suspicious of invasive disease. ${ }^{3,9,16}$ Morphologically, OSSN is divided into three main types: placoid, nodular and diffuse. ${ }^{1}$ Placoid is further sub-divided into papilliform, gelatinous and leucoplakic. ${ }^{1,17}$ It has been shown that the accuracy of clinical diagnosis by experienced clinicians is approximately $40 \%$, highlighting the need for additional diagnostic modalities. ${ }^{2}$

\section{Histology}

Histology is the gold standard for the confirmation of suspected OSSN. ${ }^{18}$ Lesions are classified according to the depth of dysplasia and integrity of the conjunctival basement membrane. ${ }^{1}$ Lesions limited to the epithelium are classified as CIN I-CIS, whereas tumours are classified as invasive when the basement membrane has been breached by nests of dysplastic cells. ${ }^{1}$ Histology typically shows thickened and disorganised epithelium with mitotic figures above the basal epithelium. There is sometimes an abrupt transition between the normal and dysplastic epithelia. Surface keratinisation can be seen, in addition to papillary arrangements, in some patients. An inflammatory infiltrate, mainly chronic, is noted at times in the underlying stroma. The cells have a high nuclear:cytoplasmic ratio with hyperchromatic nuclei (Figure 2a). ${ }^{1,3}$ Two rare variants of OSSN can be diagnosed by histology: mucoepidermoid carcinoma and spindle cell carcinoma. ${ }^{19}$ These are locally aggressive tumours with recurrence rates of up to $85 \%-100 \% .{ }^{19}$ Koilocytes are pathognomonic for HPV infection and are seen as squamous cells with a halo around the nucleus on histology. ${ }^{19}$ Immunostaining for p53, p16 and proliferation markers such as Ki67 can help confirm the diagnosis and grade of dysplasia in equivocal cases. ${ }^{3}$

The type of histology specimen is determined by the size of the lesion. Small lesions, four clock hours or less, undergo an excision biopsy that is both diagnostic and therapeutic. ${ }^{7}$ Incision biopsy is preferred for lesions greater than four clock hours, to minimise the risk of iatrogenic limbal stem cell deficiency. ${ }^{7}$ These patients will usually undergo topical chemo- or immunotherapy once the diagnosis has been confirmed. ${ }^{1}$ 
Although histology is regarded as the gold standard for diagnosis, it requires surgery that carries risk. If the surgery is performed to remove the lesion completely, this is both a diagnostic and therapeutic modality. With the success of topical therapeutic options, there has been an increased uptake of less invasive diagnostic modalities, thereby keeping diagnosis and management in the outpatient setting and decreasing the appeal of surgery for diagnosis.

\section{Cytology}

Cytology uses the principle of surface cell exfoliation to determine the presence of dysplastic cells. ${ }^{1}$ These cells are well suited to this technique, as they desquamate easily because of poor intercellular adhesion. ${ }^{1}$ As this is only a sample of the surface cells, it cannot accurately determine the stage of disease and is not therapeutic in nature. ${ }^{1}$ The key benefits of cytology are as follows:
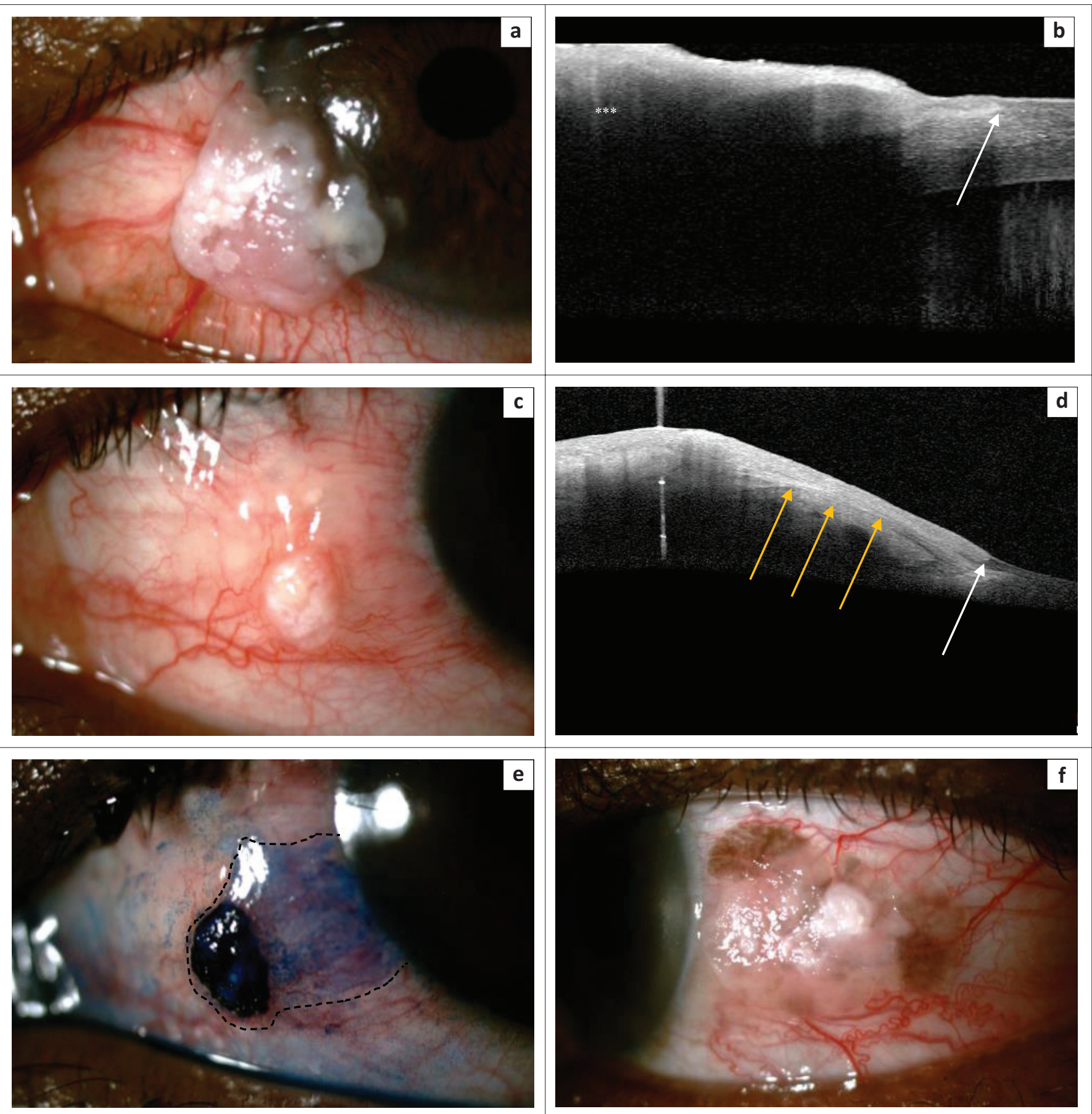

Source: Images captured by Dr R. Höllhumer

FIGURE 1: ( $a$ and b) Anterior segment photograph and anterior segment-optical coherence tomography of a leucoplakic lesion with feeder vessels. Anterior segmentoptical coherence tomography (b) showing the transition zone (white arrow) with thickened hyper-reflective epithelium. The leucoplakia has caused shadowing that has masked the demarcation line (white asterisk). (c-e) Anterior segment photographs and anterior segment-optical coherence tomography of a gelatinous lesion. Anterior segment-optical coherence tomography (d) showing the transition zone (white arrow), thickened hyper-reflective epithelium and demarcation line (yellow arrows). (e) The methylene blue stain highlights the extent of the lesion (black dotted line) that is not clinically obvious on slit lamp examination. (f-h) Anterior segment photos and anterior segment-optical coherence tomography of a leucoplakic lesion. The anterior segment-optical coherence tomography (g) shows classic features of ocular surface squamous neoplasia. The methylene blue stain $(\mathrm{h})$ delineates the margins of the lesion. 

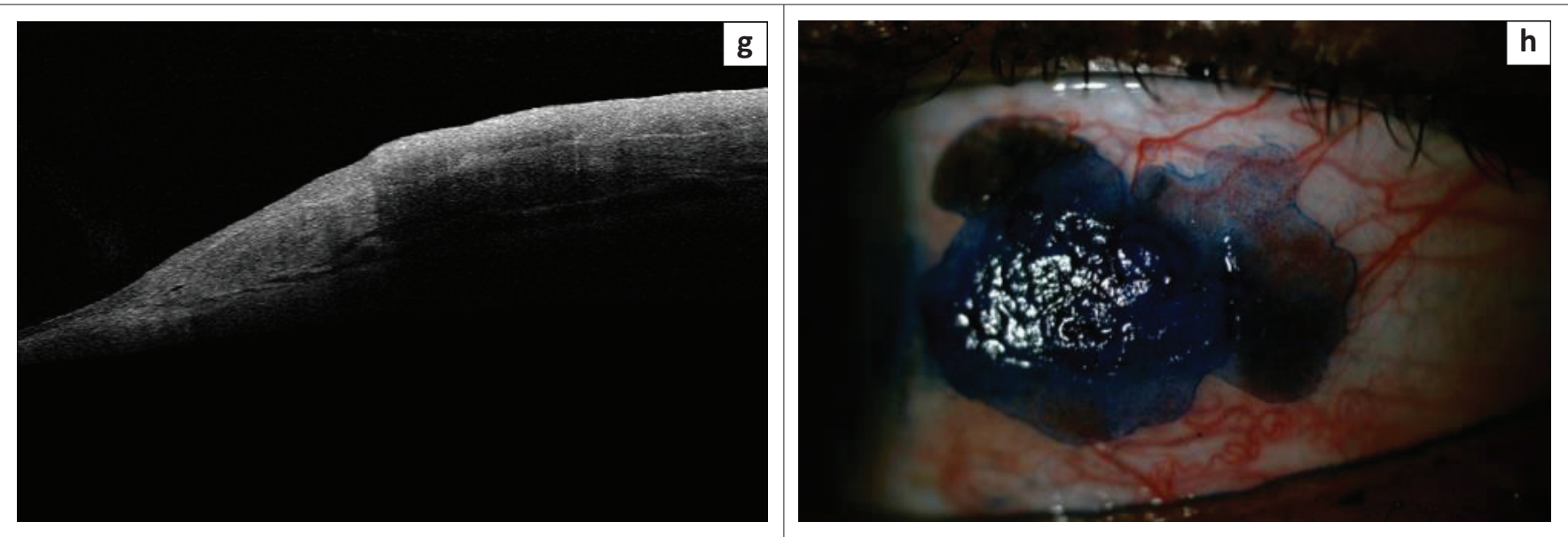

Source: Images captured by Dr R. Höllhumer

FIGURE 1 (Continues...): (a and b) Anterior segment photograph and anterior segment-optical coherence tomography of a leucoplakic lesion with feeder vessels. Anterior segment-optical coherence tomography (b) showing the transition zone (white arrow) with thickened hyper-reflective epithelium. The leucoplakia has caused shadowing that has masked the demarcation line (white asterisk). (c-e) Anterior segment photographs and anterior segment-optical coherence tomography of a gelatinous lesion. Anterior segment-optical coherence tomography (d) showing the transition zone (white arrow), thickened hyper-reflective epithelium and demarcation line (yellow arrows). (e) The methylene blue stain highlights the extent of the lesion (black dotted line) that is not clinically obvious on slit lamp examination. (f-h) Anterior segment photos and anterior segment-optical coherence tomography of a leucoplakic lesion. The anterior segment-optical coherence tomography (g) shows classic features of ocular surface squamous neoplasia. The methylene blue stain (h) delineates the margins of the lesion.
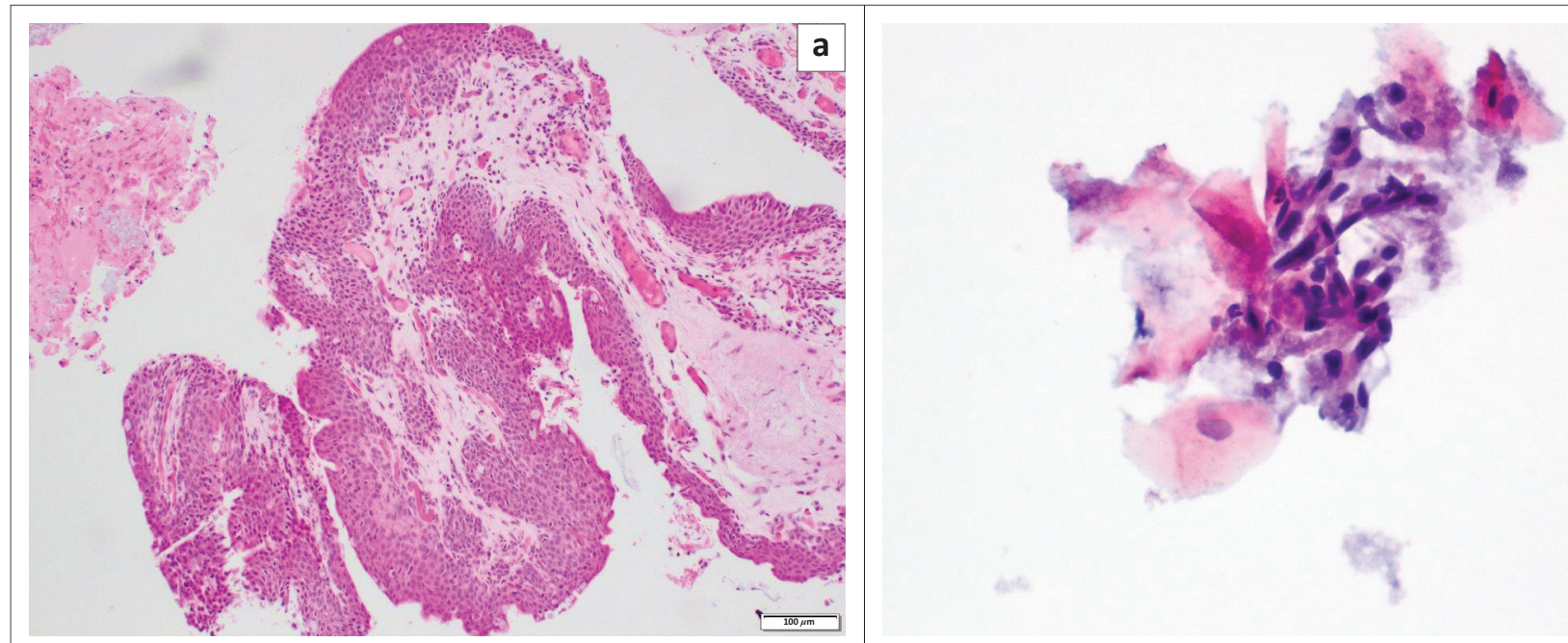

Source: Images captured by Prof. P. Michelow

FIGURE 2: (a) Conjunctival biopsy comprising thickened epithelium with full thickness involvement by dysplastic cells showing a high nuclear:cytoplasmic ratio. The basement membrane remains intact. This is consistent with a pterygium showing conjunctival intra-epithelial neoplasia $3 /$ high grade squamous intraepithelial lesion (haematoxylin + eosin, $\times 100$ magnification). Case courtesy of Dr Eunice van der Berg, University of the Witwatersrand and National Health Laboratory Service, Chris Hani Baragwanath Hospital, Johannesburg. (b) Impression cytology of the same case demonstrating loosely cohesive clusters of squamous cells with a very high nuclear:cytoplasmic ratio, irregular nuclear contours and hyperchromasia consistent with a high-grade squamous intraepithelial lesion (ThinPrep, Papanicolaou stain, $\times 400)$.

- Provides a source of intact epithelial cells for cytological assessment;

- It is simple to perform, being done on an outpatient basis;

- Minimally invasive, by using only topical anaesthesia, and can be performed on children;

- Repeatable, allowing one to monitor response to treatment and diagnose recurrent disease without the need for additional surgery;

- Limits the complications of repeated surgery by preserving limbal stem cells and sparing the conjunctiva;

- Can be used to distinguish between pathologies in patients with complex ocular surfaces (limbal stem cell failure, pannus and pterygium);

- If liquid-based cytology (LBC) is being utilised, then ancillary techniques such as polymerase chain reaction
(PCR) can be performed on the same specimen without additional specimens required..$^{1,20,21,22}$

Numerous methods have been described for the collection of a cytology specimen. A spatula can be used to scrape off the surface cells, a cyto-brush that was designed for Papanicolaou smears can exfoliate cells or a fluid-filled tuberculin syringe can aspirate cells from the surface ${ }^{1,15}$ More commonly used is nitrocellulose paper that is imprinted onto the surface of the lesion. With impression, the cells are trapped on the surface and in the pores of the membrane before being placed in a transport medium for analysis. ${ }^{1}$ The pore size is important as it affects the cellularity and cellular integrity of the specimen..$^{21}$ Larger pore size increases cellularity, whereas smaller pore size preserves cellular morphology. ${ }^{21}$ A pore size of 
$0.025-0.45 \mu \mathrm{m}$ is recommended. ${ }^{21}$ False negatives are associated with keratotic lesions and in early disease where dysplastic cells reside in the basal epithelial cell layers. ${ }^{20,21}$ Repeated application of the collection method has been shown to improve the yield, as progressively deeper layers are desquamated. ${ }^{20,21}$

Cells can either be transported to a laboratory for immediate analysis or be stored in a medium. Specimens are traditionally placed in alcohol, which maintains the integrity of the specimen for several weeks. ${ }^{1}$ Alternatively the cells can be placed in a LBC medium. Liquid-based cytology is an alternative technique to process specimens for microscopic evaluation. ${ }^{23}$

Specimens for cytology are mostly assessed by light microscopy after the application of stains, such as periodic acid-Schiff, haematoxylin-eosin, Gill's haematoxylin and Papanicolaou. The Papanicolaou stain is used for LBC specimens and is useful to identify changes in surface epithelium of the conjunctiva. ${ }^{21}$ Features of cellular atypia include a high nuclear:cytoplasmic ratio with nuclear enlargement, irregular nuclear contours and hyperchromasia (Figure 2b). The nuclei of invasive squamous cell carcinoma can show areas of chromatin clumping and parachromatin clearing, and prominent nucleoli. ${ }^{21}$ Nolan et al. ${ }^{24}$ provide a detailed description of the cytological features of OSSN on impression cytology. Barros et al. ${ }^{25}$ adapted the criteria for abnormal cytological features on impression cytology to develop a predictive score to distinguish CIN and squamous cell carcinoma (SCC). ${ }^{25}$ They took the following parameters into account when developing the score: nuclear enlargement, hyperchromasia, prominent nucleoli, syncytial-like groupings, increased nuclear:cytoplasmic ratio, eosinophilic cytoplasm and absence of distinct cytoplasmic borders. They found that a score of 4.25 distinguishes CIN from invasive malignancy with a sensitivity of $95 \%$ and a specificity of 93\% ${ }^{25}$ Abnormal cytological findings may persist for up to six weeks after topical mitomycin-C. This should be kept in mind when reviewing the results of a cytology specimen after completing topical medical therapy. ${ }^{1,21}$

Semenova et al. ${ }^{26}$ assessed the concordance between cytology and histopathology in the diagnosis of OSSN, by using a spatula for removing surface cells and immersing specimens in $95 \%$ ethyl alcohol. They found an $80 \%$ concordance between the two methods for the diagnosis of OSSN, but a poor concordance for the histological grade. ${ }^{26}$ Management of OSSN is primarily based on the size of the lesion rather than the histological grade, limiting the clinical impact of this shortcoming. Barros et $\mathrm{al}^{22}$ assessed the sensitivity and specificity of specimens for impression cytology fixed in a solution of acetic acid, formaldehyde and ethyl alcohol, compared with the gold standard histology. They found that the specimens for impression cytology had a sensitivity of $92 \%$ and a specificity of $94 \%$. Tole et al. ${ }^{27}$ evaluated the correlation between impression cytology (IC) and histology by using a biopore membrane fixed onto a plastic device. This made it easy to perform IC, and the specimens were immersed in $95 \%$ alcohol. ${ }^{27}$ There was a correlation in $80 \%$ of cases with no false positives. ${ }^{27}$ All three studies found that the presence of keratin negatively affected the cellularity of the specimens and therefore decreased the sensitivity of cytology.

Impression cytology is therefore an easy and minimally invasive diagnostic method to perform in the outpatient setting. It has a high sensitivity and specificity, which can be negatively impacted by keratotic and early lesions. Two of the key benefits of this diagnostic modality are the ability to sample a complex ocular surface and its repeatability.

\section{Anterior segment-optical coherence tomography}

Optical coherence tomography uses a light source with an interferometer to create an interference pattern that combines to produce a high-resolution, cross-sectional image of the ocular surface. ${ }^{15,28}$ Commercially available devices are able to produce images with a resolution of $5 \mu \mathrm{m}$, whilst custom devices in research centres are able to produce images with a resolution of $3 \mu \mathrm{m} .{ }^{15}$ Three features that characterise OSSN on AS-OCT are a thickened hyper-reflective epithelium, abrupt transition from the normal to abnormal epithelium and a demarcation line (Figure 1b, d, g). Anterior segment-optical coherence tomography angiography was recently described as a modality that can additionally image the vasculature network around a conjunctival mass..$^{29}$ Liu et al. ${ }^{29}$ found that the vessel density was highest in the $200 \mu \mathrm{m}$ of subepithelial tissue under the tumour. Anterior segment-optical coherence tomography is a useful modality as it is noncontact, simple, repeatable and able to diagnose OSSN on complex ocular surfaces (limbal stem cell failure, pannus, scarring, pterygium). ${ }^{15,30}$ Image quality is affected by the presence of keratin, which can mask the underlying tissue (Figure 1b); however, images of areas adjacent to the keratin will often show features of abnormal epithelium. ${ }^{15}$ Anterior segment-optical coherence tomography is useful not only in the diagnosis of disease, but also for monitoring the response to medical management and early identification of recurrence. ${ }^{31}$ Nanji et al..$^{32}$ showed in their study that the epithelial profile of OSSN normalises with response to topical medical therapy.

Atallah et al. ${ }^{30}$ performed a study to assess the ability of AS-OCT to distinguish different pathologies in patients with a complex ocular surface. Histology was performed on all cases as the current gold standard to exclude OSSN. All cases with OSSN were picked up by OCT, whilst OSSN was excluded in cases with other ocular surface pathologies such as ocular rosacea, pterygia or pinguecula, Salzman's nodular degeneration, mucous membrane pemphigoid, corneal scarring and limbal stem cell deficiency. ${ }^{30}$ Kieval et al. $^{33}$ assessed the use of a custom-made ultra-highresolution AS-OCT for diagnosing OSSN. They found that using an epithelial thickness cut-off of $142 \mu \mathrm{m}$ had a sensitivity of $94 \%$ and a specificity of $100 \%,{ }^{33}$ whereas a 
study by Nanji et al. ${ }^{32}$ found that a thickness of $120 \mu \mathrm{m}$ had a sensitivity and specificity of $100 \%$. Leucoplakic or very thick lesions caused shadowing, which made it difficult to view the underlying tissue and obscured the plane between the normal and abnormal tissue. ${ }^{33}$ A thickness of greater than $465 \mu \mathrm{m}$ has been found to be the limit for identifying a tumour plane. ${ }^{32}$

Singh et al..$^{34}$ used AS-OCT to distinguish CIN from invasive SCC. They found the classic thickened hyper-reflective epithelium for both tumour grades. Invasive SCC however had an absent plane of separation (100\% invasive SCC vs. $0 \%$ CIN) and hypo-reflective pockets in the substantia propria of the conjunctiva ( $57 \%$ invasive SCC vs. $0 \% \mathrm{CIN}){ }^{34}$

Anterior segment-optical coherence tomography is a valuable non-invasive diagnostic modality, which is easy to use and repeatable. The key difficulty encountered with commercially available devices is assessing the epithelial profile in keratotic and thick lesions. Although this may make it difficult to assess the epithelium over the centre of the lesion, the surrounding epithelium will usually have the hallmarks of OSSN.

\section{Vital dyes}

Vital dyes that can be used to assist in the diagnosis of OSSN include Rose Bengal, toluidine and methylene blue. ${ }^{15}$

Rose Bengal is a derivative of fluorescein that stains unhealthy and dead epithelial cells a bright pink colour. ${ }^{15}$ It therefore dyes OSSN lesions and delineates the abnormal epithelium. ${ }^{15}$ Other conditions with an abnormal epithelium may also stain with this dye, making it a test with high sensitivity and poor specificity. ${ }^{15}$

Methylene blue is an acidophilic dye that can penetrate cell walls and bind to nucleic acid. It therefore has an affinity for cells with a high metabolic rate and stains OSSN lesions (Figure 1e, h). ${ }^{15}$ Steffen et al. ${ }^{35}$ conducted a prospective study of 75 participants to assess the diagnostic value of $1 \%$ methylene blue. They described a sensitivity of $97 \%$, a specificity of $50 \%$, a positive predictive value of $60 \%$ and a negative predictive value of $96 \%{ }^{35}$

Toluidine blue, a metachromatic acidophilic dye, has an affinity for cells with high-density nuclear material, high mitotic rate and cells with poor intercellular adhesion, which are all properties of OSSN lesions. ${ }^{15,36,37}$ It also stains mast cells, inflammatory cells and injured cells. ${ }^{38}$ Gichuhi et al. ${ }^{36}$ performed a study with 537 participants to determine the safety and accuracy of toluidine $0.05 \%$ in distinguishing OSSN from benign lesions. They found that there was no surface toxicity and only a mild discomfort with application of the drops (when used without an anaesthetic). ${ }^{36}$ The stain had a high sensitivity of $92 \%$, but a low specificity of $31 \%$ for diagnosis of OSSN when compared with the gold standard, histology. ${ }^{36}$ This translates to a positive predictive value of
$41 \%$, negative predictive value of $88 \%$ and an inter-observer agreement of $91 \% .{ }^{36}$ In contrast to the other studies, Romero et al. ${ }^{37}$ found a $100 \%$ sensitivity and $90 \%$ specificity with $1 \%$ toluidine blue dye, with a $100 \%$ inter-observer agreement. ${ }^{37}$

The vital dyes therefore all have a high sensitivity and low specificity. This makes them useful to exclude the diagnosis of OSSN, with a good negative predictive value. They can also be used during surgery to delineate a lesion and guide margins for excision.

\section{Confocal microscopy}

In vivo confocal microscopy (IVCM) is a minimally invasive imaging modality that can produce en-face images of the ocular surface at a cellular level. ${ }^{15,39}$ There are contact and non-contact versions of this technology, with image acquisition and interpretation being operator dependent. ${ }^{15}$ The advantages of IVCM is that it is minimally invasive and can be performed in the outpatient setting, avoiding the need for surgery if medical options are used for treatment. ${ }^{39}$ Limitations of this modality include the inability to re-image the same area over multiple visits, technically difficult interpretation of the images and the inability to scan lesions at a depth greater than $500 \mu \mathrm{m} .{ }^{39}$

Images suspicious of OSSN show a classic 'starry night' appearance with hyper-reflective pleomorphic cells, a middle cell layer with prominent nucleoli that are seen as bright dots, mitotic cells (seen as cells with two bright dots), poorly defined basal cell layer with bright nuclei, absence of sub-basal nerves and an abrupt transition between the normal and abnormal epithelia. . $^{15,16,18}$ The 'loss' of the sub-basal nerve plexus probably represents the decreased visibility on the images because of the high reflectivity of the CIN cells; therefore, with resolution of the lesions there is a reappearance of the nerve plexus. ${ }^{18}$ Like with impression cytology, results are negatively affected by the presence of keratin. ${ }^{15}$

Studies that have assessed the usefulness of this modality have shown conflicting results. Nguena et al. ${ }^{16}$ conducted a case-control study with 44 cases and 57 controls. They did not find any significant difference in the images between the two groups, with a sensitivity and specificity for identifying OSSN of $39 \%$ and $67 \%$, respectively. ${ }^{16}$ Cinotti et al. ${ }^{40}$ conducted a study by using a handheld in vivo reflectance confocal microscope to assess conjunctival lesions. They also concluded that the above-listed criteria were not valid and found a greater association with epithelial cells greater than $20 \mu \mathrm{m}$ and OSSN. ${ }^{40}$ Alomar et al. ${ }^{18}$ described the above criteria in four patients with OSSN in their pilot study, whilst $\mathrm{Xu}$ et $\mathrm{al} .{ }^{41}$ found that IVCM could both diagnose OSSN and distinguish the degree of invasion.

The heterogeneity of these results may highlight the importance of an experienced operator and interpreter of 
images. At this time, IVCM is limited to an adjunctive modality to other better-established diagnostic modalities.

\section{Ultra-sound biomicroscopy}

Ultra-sound biomicroscopy uses a high-frequency ultrasonography of $20-50 \mathrm{MHz}$ to produce images with a resolution of up to $25 \mu \mathrm{m}$ and to a depth of $6 \mathrm{~mm} \cdot{ }^{42}$ It is performed in an eyebath with the patient in a supine or reclined position. ${ }^{42}$ This makes it an uncomfortable procedure to undergo and necessitates an experienced operator to perform. It has been shown to be superior to AS-OCT for delineating larger, deeper and pigmented anterior segment tumours, as it does not suffer the same shadowing effect as AS-OCT, whereas AS-OCT has been found to give higherresolution imaging for superficial non-pigmented conjunctival tumours. ${ }^{42}$

\section{Conclusion}

Ocular surface squamous neoplasia is the most common ocular cancer. It is suspected in conjunctival lesions that are elevated, vascularised, have a pearly grey appearance and a variable amount of pigmentation. Clinical diagnosis has however been shown to be only $40 \%$ accurate, highlighting the need for additional diagnostic modalities. ${ }^{2}$ The gold standard for diagnosis is histology, which has been used as both a diagnostic and therapeutic modality. Surgery has risks and requires hospital admission, even if it is performed as a day case. There has therefore been a move to the use of medical therapy that can be performed on an outpatient basis and that treats the entire ocular surface. With this, less invasive diagnostic modalities have replaced histology. These include cytology, AS-OCT, vital dyes, confocal microscopy and ultra-sound biomicroscopy. These modalities all have the benefit of being the procedures that are repeatable and can be performed in an outpatient setting. Cytology has the additional benefit of being able to conduct additional tests, such as PCR for HPV infection. Anterior segmentoptical coherence tomography and cytology are both able to identify OSSN on a complex ocular surface where surgery would be a poor diagnostic modality of choice. In vivo confocal microscopy and UBM have had a poorer uptake because of the technical difficulty in acquiring and interpreting images, whilst vital dyes are useful to exclude OSSN with high negative predicative values. The best diagnostic modality is likely a combination of AS-OCT and cytology. Cytology allows for a pathological diagnosis, whilst the imaging has the benefit of visually monitoring the response to medical therapy. The association between OSSN and HPV infection remains unclear in the literature. Future research could look at the use of LBC as a diagnostic modality with supplementary HPV PCR to improve our understanding of this association.

\section{Acknowledgements}

The authors thank the staff at the Wits Health Sciences library.

\section{Competing interests}

The authors have declared that no competing interests exist.

\section{Authors' contributions}

All authors contributed equally to this work.

\section{Ethical consideration}

Approval to conduct the study was received from the Human Research Ethics Committee of the University of the Witwatersrand (M190729).

\section{Funding information}

This research received no specific grant from any funding agency in the public, commercial or not-for-profit sectors.

\section{Data availability statement}

Data sharing is not applicable to this article.

\section{Disclaimer}

The views and opinions expressed in this article are those of the authors and do not necessarily reflect the official policy or position of any affiliated agency of the authors.

\section{References}

1. Basti S, Macsai MS. Ocular surface squamous neoplasia. Cornea. 2003;22(7): 687-704. https://doi.org/10.1097/00003226-200310000-00015

2. Lee GA, Hirst LW. Ocular surface squamous neoplasia. Surv Ophthalmol. 1995;39(6):429-450. https://doi.org/10.1016/s0039-6257(05)80054-2

3. Tananuvat N, Lertprasertsuke N. Ocular surface squamous neoplasia. In: Srivastava S, editor. London: Intraepithelial neoplasia. InTech; 2012. https://doi.org/ $10.5772 / 32238$

4. Gichuhi S, Sagoo MS, Weiss HA, Burton MJ. Epidemiology of ocular surface squamous neoplasia in Africa. Trop Med Int Health. 2013;18(12):1424-1443. https://doi.org/10.1111/tmi.12203

5. Hollhumer R, Williams S, Michelow P. Ocular surface squamous neoplasia: Population demographics, pathogenesis and risk factors. Afr Vis Eye Health. 2020;79(1):a553. https://doi.org/10.4102/aveh.v79i1.553

6. Gichuhi S, Ohnuma S, Sagoo MS, Burton MJ. Pathophysiology of ocular surface squamous neoplasia. Exp Eye Res. 2014;129(1):172-182. https://doi.org/ 10.1016/j.exer.2014.10.015

7. Shields $\mathrm{CL}$, Shields JA. Tumors of the conjunctiva and cornea. Surv Ophthalmol. 2004;49(1):3-24. https://doi.org/10.1016/j.survophthal.2003.10.008

8. Shields $\mathrm{CL}$, Chien JL, Surakiatchanukul T, et al. Conjunctival tumors: Review of clinical features, risks, biomarkers, and outcomes - The 2017 J. Donald M. Gass Lecture. Asia-Pac J Ophthalmol. 2017;6(2):109-120. https://doi.org/10.22608/ APO. 201710

9. Gichuhi S, Macharia E, Kabiru J, et al. Clinical presentation of ocular surface squamous neoplasia in Kenya. JAMA Ophthalmol. 2015;133(11):1305. https://doi. org/10.1001/jamaophthalmol.2015.3335

10. Amin MB, Edge SB, Greene FL, et al., editors. AJCC cancer staging manual. Cham: Springer International Publishing; 2017 [cited 2019 Dec 17]. Available from https://www.springer.com/gp/book/9783319406176

11. Bellerive C, Berry JL, Polski A, Singh AD. Conjunctival squamous neoplasia: Staging and initial treatment. Cornea. 2018;37(10):1287-1291. https://doi.org/10.1097/ ICO.0000000000001651

12. Tabbara KF, Kersten R, Daouk N, Blodi FC. Metastatic squamous cell carcinoma of the conjunctiva. Ophthalmology. 1988;95(3):318-321. https://doi.org/10.1016/ S0161-6420(88)33180-5

13. Singh S, Mohamed A, Kaliki S. Ocular surface squamous neoplasia: Analysis based on the 8th American Joint Committee on Cancer classification. Int Ophthalmol. 2019;39(1):1283-1291. https://doi.org/10.1007/s10792-018-0943-x

14. Margo CE, Mancera N. Determining tumor category of ocular surface squamous neoplasia: Science or art? Ann Transl Med. 2018;6(Suppl 2):S121-S121. https:// doi.org/10.21037/atm.2018.12.15 
15. Nanji AA, Mercado C, Galor A, Dubovy S, Karp CL. Updates in ocular surface tumo diagnostics. Int Ophthalmol Clin. 2017;57(3):47-62. https://doi.org/10.1097/ diagnostics. Int Ophthain

16. Nguena MB, Van Den Tweel JG, Makupa W, et al. Diagnosing ocular surface squamous neoplasia in East Africa. Ophthalmology. 2014;121(2):484-491. https://doi.org/10.1016/j.ophtha.2013.09.027

17. Honavar S, Manjandavida F. Tumors of the ocular surface: A review. Indian Ophthalmol. 2015;63(3):187. https://doi.org/10.4103/0301-4738.156912

18. Alomar TS, Nubile M, Lowe J, et al. Corneal intraepithelial neoplasia: In vivo confocal microscopic study with histopathologic correlation. Am J Ophthalmol. 2011;151(2):238-247. https://doi.org/10.1016/j.ajo.2010.08.035

19. Mittal R, Rath S, Vemuganti GK. Ocular surface squamous neoplasia - Review of etio-pathogenesis and an update on clinico-pathological diagnosis. Saudi Ophthalmol. 2013;27(3):177-186. https://doi.org/10.1016/j.sjopt.2013.07.002

20. Huerva V, Ascaso FJ. Conjunctival intraepithelial neoplasia - Clinical presentation diagnosis and treatment possibilities. In: Srivastava S, editor. Intraepithelia neoplasia. West Palm Beach, Florida: InTech; 2012, pp. 79-102.

21. Barros JN, Almeida SRA, Lowen MS, Cunha MC, Gomes JA. Impression cytology in the evaluation of ocular surface tumors: Review article. Arq Bras Oftalmol. 2015;78(2):126-132. https://doi.org/10.5935/0004-2749.20150033

22. Barros JN, Lowen MS, Moraes-Filho MN, Martins MC. Use of impression cytology for the detection of unsuspected ocular surface squamous neoplasia cells in pterygia. Arq Bras Oftalmol. 2014;77(5):305-309. https://doi.org/10.5935/0004

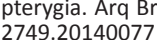

23. Martini M, Capodimonti S, Cenci T, et al. To obtain more with less: Cytologic samples with ancillary molecular techniques - The useful role of liquid-based cytology. Arch Pathol Lab Med. 2018;142(3):299-307. https://doi.org/10.5858/ cytology. Arch Pathol

24. Nolan GR, Hirst LW, Bancroft BJ. The cytomorphology of ocular surface squamous neoplasia by using impression cytology. Cancer Cytopathol. 2001;93(1):60-67. https://doi.org/10.1002/1097-0142(20010225)93:1<60::AID-CNCR9008>3.0. CO;2-5

25. Barros JN, Lowen MS, Ballalai PL, Mascaro VLDM, Gomes JÁP, Martins MC Predictive index to differentiate invasive squamous cell carcinoma from preinvasive ocular surface lesions by impression cytology. $\mathrm{Br} J$ Ophthalmol. 2009;93(2):209-214. https://doi.org/10.1136/bjo.2008.147710

26. Semenova EA, Milman T, Finger PT, et al. The diagnostic value of exfoliative cytology vs. histopathology for ocular surface squamous neoplasia. Am Ophthalmol. 2009;148(5):772-778.e1. https://doi.org/10.1016/j.ajo.2009.06.015

27. Tole DM. Reliability of impression cytology for the diagnosis of ocular surface squamous neoplasia employing the Biopore membrane. Br J Ophthalmol. 2001;85(2):154-158. https://doi.org/10.1136/bjo.85.2.154

28. Thomas BJ, Galor A, Nanji AA, et al. Ultra high-resolution anterior segment optical coherence tomography in the diagnosis and management of ocular surface squamous neoplasia. Ocul Surf. 2014;12(1):46-58. https://doi.org/10.1016/j. jtos.2013.11.001
29. Liu Z, Karp CL, Galor A, Al Bayyat GJ, Jiang H, Wang J. Role of optical coherence tomography angiography in the characterization of vascular network patterns of ocular surface squamous neoplasia. Ocul Surf. 2020;18(4): 926-935. https://doi. org/10.1016/j.jtos.2020.03.009

30. Atallah M, Joag M, Galor A, et al. Role of high resolution optical coherence tomography in diagnosing ocular surface squamous neoplasia with coexisting ocular surface diseases. Ocul Surf. 2017;15(4):688-695. https://doi.org/10.1016/j. jtos.2017.03.003

31. Sayed-Ahmed IO, Palioura S, Galor A, Karp CL. Diagnosis and medical management of ocular surface squamous neoplasia. Expert Rev Ophthalmol. 2017;12(1):11-19. https://doi.org/10.1080/17469899.2017.1263567

32. Nanji AA, Sayyad FE, Galor A, Dubovy S, Karp CL. High-resolution optical coherence tomography as an adjunctive tool in the diagnosis of corneal and conjunctival pathology. Ocul Surf. 2015;13(3):226-235. https://doi.org/10.1016/j.jtos.2015.02.001

33. Kieval JZ, Karp CL, Shousha MA, et al. Ultra-high resolution optical coherence tomography for differentiation of ocular surface squamous neoplasia and Pterygia. Ophthalmology. 2012;119(3):481-486. https://doi.org/10.1016/j. ophtha.2011.08.028

34. Singh S, Mittal R, Ghosh A, et al. High-resolution anterior segment optical coherence tomography in intraepithelial versus invasive ocular surface squamous neoplasia. Cornea. 2018;37(10):1292-1298. https://doi.org/10.1097/ICO.0000000000001680

35. Steffen J, Rice J, Lecuona K, Carrara H. Identification of ocular surface squamous neoplasia by in vivo staining with methylene blue. $\mathrm{Br} J$ Ophthalmol. 2014;98(1):13-15. https://doi.org/10.1136/bjophthalmol-2013-303956

36. Gichuhi S, Macharia E, Kabiru J, et al. Toluidine blue $0.05 \%$ vital staining for the diagnosis of ocular surface squamous neoplasia in Kenya. JAMA Ophthalmol. 2015;133(11):1314. https://doi.org/10.1001/jamaophthalmol.2015.3345

37. Romero IL, Barros JN, Martins MC, Ballalai PL. The use of $1 \%$ toluidine blue eye drops in the diagnosis of ocular surface squamous neoplasia. Cornea. 2013;32(1):36-39. https://doi.org/10.1097//CO.0b013e318243f61f

38. Shields CL, Shields JA. Ocular surface squamous neoplasia: From blue skies to blue dyes - We still need our ophthalmic pathologists. JAMA Ophthalmol. 2015:133(11):1-2. https://doi.org/10.1001/jamaophthalmol.2015.3359

39. Tanaka S, Kohanim $\mathrm{S}$. The role of confocal microscopy in diagnosing ocular surface tumors. Int Ophthalmol Clin. 2017;57(1):75-85. https://doi.org/10.1097/ IIO.0000000000000146

40. Cinotti E, Perrot J-L, Labeille B, et al. Handheld reflectance confocal microscopy for the diagnosis of conjunctival tumors. Am J Ophthalmol. 2015;159(2):324-333.e1. https://doi.org/10.1016/j.ajo.2014.10.031

41. Xu Y, Zhou Z, Xu Y, et al. The clinical value of in vivo confocal microscopy for diagnosis of ocular surface squamous neoplasia. Eye. 2012;26(6):781-787. https://doi.org/10.1038/eye.2012.15

42. Bianciotto C, Shields CL, Guzman JM, et al. Assessment of anterior segment tumors with ultrasound biomicroscopy versus anterior segment optical coherence tomography in 200 cases. Ophthalmology. 2011;118(7):P1297-1302. https://doi. org/10.1016/j.ophtha.2010.11.011 